\title{
A methodology for flexibility analysis of pipeline systems
}

\author{
Journal Title XX(X): $\underline{1-\underline{18}}$ \\ (CThe Author(s) 2017 Reprints and permission: \\ sagepub.co.uk/journalsPermissions.nav DOI: 10.1177/ToBeAssigned www.sagepub.com/
}

SAGE

\section{Umer Zahid ${ }^{1,5}$, Sohaib Z. Khan ${ }^{1,2}$, Muhammad A. Khan ${ }^{3}$, Hassan J. Bukhari ${ }^{1}$, Salman Nisar ${ }^{1}$, and Kamran A. Khan ${ }^{4}$}

\begin{abstract}
Pipeline systems serve a crucial role in an effective transport of fluids to the designated location for medium to long span of distances. Owing to its paramount economic significance, pipeline design field have undergone extensive development over the past few years for enhancing optimization and transport efficiency. This research paper attempts to propose a methodology for flexibility analysis of pipeline systems through employing contemporary computational tools and practices. A methodical procedure is developed which involves modelling of the selected pipeline system in CAESAR II followed by insertion of pipe supports and restraints. The specific location and selection of the inserted supports is based on the results derived from the displacement, stress, reaction and nozzle analysis of the concerned pipeline system. Emphasis is laid on the compliance of the design features to the leading code of pipeline transportation systems for liquid and slurries, ASME B31.4. The discussed procedure and approach can be successfully adjusted for analysis of various other types of pipeline system configuration. In addition to the provision of systematic flow in analysis, the method also improves efficient time saving practices in pipeline stress analysis.
\end{abstract}

\section{Keywords}

Pipeline, flexibility analysis, CAESAR II, ASME B31.4

\section{Nomenclature}

a Linear expansion coefficient, $\mathrm{m} / \mathrm{m}^{\circ} \mathrm{C}$.

Inner diameter, $\mathrm{m}$

$d_{o} \quad$ Outer diameter, $\mathrm{m}$.

e Weld join factor as defined in Table 403.2.1-1 of ASME B31.4.

$p$ Internal design pressure inside the pipe, $\mathrm{N} / \mathrm{m}^{2}$.

$t \quad$ Thickness of circular cross section, $\mathrm{m}$. $\mathrm{v}$ Poisson ratio for the material.

Published by SAGE. This is the Author Accepted Manuscript issued with: Creative Commons Attribution Non-Commercial License (CC:BY:NC 4.0). The final published version (version of record) is available online at DOI:10.1177/0954408918812275. Please refer to any applicable publisher terms of use. 
$t_{m} \quad$ minimum allowable wall thickness, $\mathrm{m}$.

Inner diameter, $\mathrm{m}$.

Modulus of elasticity of pipe in $\mathrm{N} / \mathrm{m}^{2}$.

\footnotetext{
${ }^{1}$ Department of Engineering Sciences, PN Engineering College, National University of Sciences and Technology, Karachi, Pakistan.

${ }^{2}$ Department of Mechanical Engineering, Faculty of Engineering, Islamic

University of Madinah, Madinah, PO Box 170, Kingdom of Saudi Arabia. ${ }^{3}$ School of Aerospace, Transport and Manufacturing, Cranfield University, Cranfield, Bedfordshire, UK.

${ }^{4}$ Khalifa University of Science, Technology and Research (KUSTAR),

Abu Dhabi, UAE.

${ }^{5}$ Department of Mechanical and Aerospace Engineering, Polytechnic University of Turin, 10129, Turin, Italy.
}

Corresponding author:

Sohaib Z. Khan

Email: szkhan@iu.edu.sa; sohaib.khan@pnec.nust.edu.pk

I Moment of inertia of pipe, $\mathrm{m}^{4}$.

$L \quad$ Span Length, $\mathrm{m}$.

$P \quad$ Internal pressure inside the pipe, $\mathrm{N} / \mathrm{m}^{2}$.

$S \quad 72 \%$ of specified minimum yield strength fornew pipe of known specifications obtained from

Table 403.2.1-1 of ASME B31.4, Pa.

$S_{A} \quad$ Allowable stress range, $\mathrm{Pa}$.

$S_{E} \quad$ Displacement stress range, $\mathrm{Pa}$

$S_{L} \quad$ Longitudinal stress due to pressure and external loading conditions, $\mathrm{Pa}$.

$S_{h} \quad$ Circumferential (hoop) stress due to internal pressure, Pa.

$S_{y} \quad$ Specified minimum yield strength obtained from Table 403.2.1-1 of ASME B31.4, Pa.

$\Delta T$ Difference between operating and installed temperature, ${ }^{\circ} \mathrm{C}$.

$W \quad$ Uniformly distributed weight of piping, $\mathrm{N} / \mathrm{m}$.

$W_{c} \quad$ Concentrated weight on piping, N.

\section{Introduction}

Design and flexibility analysis of pipeline networks have evolved in to an increasingly comprehensive and diversified discipline due to the rapid industrial development and rise in fuel demand on the global scale [1]. The characteristic and well defined set of rules for ensuring pipeline functionality and safety of personnel are typically referenced from Code of Federal Regulations Title 49 [2, 3]. Due to the occurrence of simultaneous several loading conditions, pipeline systems particularly in oil and gas field requires a systematic consideration of design factors involved [4]. Varying degree of design complexity and constructional constraints have led to the creation of numerous calculations procedures and sizing methods to achieve an accurate and optimized design before actual pipeline installation phase $[\underline{5}, \underline{6}]$.

Pipeline design analysis is substantially different from that of plapt piping due to its distinctive characteristic 
features [7]. Due to lack of turns in pipeline routing, stresses

encountered in pipelines are predictable and can therefore be associated with higher allowable stress limits. To achieve higher allowable stresses and prevent the occurrence of strain follow up during operation, pipeline material has preferably higher yield strength to ultimate strength ratio value. Pressure elongation contributes most to the pipeline axial movement in contrast with plant piping where thermal expansion effects are significant. Additional structural and design regulations must be addressed in the case of buried underground pipelines due to soil-pipe interaction which does not occur in piping of plant systems.

Flexibility analysis ensures the structural integrity of pipeline systems in the presence of multiple loading conditions like pressure, temperature, weight and occasional loads for enabling continuous operation of the pipeline network [8]. Furthermore, the analysis requires adherence to codes and standards which not only guarantees safety but lead to standardization and subsequent efficiency in piping item selection [9]. Four major design parameters are addressed in flexibility analysis which are as follows:

1) Displacement occurring within the pipeline system.

2) Stress distribution resulting from loads exerted on the pipeline system.

3) Reaction loads applied on the supporting structure by the pipeline system.

4) Allowable forces and moments that the pipeline system can impose on the nozzles of the connected equipment.

This paper is specifically aimed towards extending the design methodology proposed for plant piping flexibility analysis in [10] to pipeline configuration systems. Analysis is carried out under the design operating conditions persisting in the system and is focused primarily on the selection and placement of supports and restraints based on output results from displacement, stress, reaction and nozzle analysis. Design is in accordance with ASME B31.4 and incorporates other design constraints as specified by the client and industry. CAESAR II software, a renowned piping

computational tool for stress and flexibility analysis is extensively utilized along with relevant applied mathematical calculations for determining aspects of displacements and stresses occurring in the selected model. The proposed method of analysis is based on the systematic and perceptive combination of theoretical and software approach to achieve an optimum support layout for pipeline network.

\section{Literature Review \& Methodology}

Like various other well established and renowned specialized fields, majority of the previously conducted research revolved around results derived from either theoretical, software or experimental analysis [11]. Extensive research studies have been performed based on theoretical analysis which were prevalent in the pioneering stages of the pipe stress analysis field. A numerical method for evaluating the maximum stress value in the pipeline network is derived leading to fourth degree of polynomial equation development. The proposed method has a much-simplified 
application approach in comparison with a typical finite element method [12]. An appreciable emphasis has been laid on the evaluation of allowable limits of pipeline stresses and their subsequent significance in relation with different stress criterion [13].

An analysis for the determination of stresses resulting from dead weight in piping system in conjunction with those resulting from thermal expansion loads is conducted as an extension to the previously established Meyer-Hovgaard and grapho-analytical methods [14]. A case study has been conducted to assess the occurrence of failure conditions in a pipeline system due to the high-pressure flammable gas jet release. The analysis is centered around three different case scenarios through which the pipeline systems and its adjacent piping network might be affected [15].

Analysis of failure resulting from stress corrosion cracking in a stainless-steel pipeline system is highlighted in one study. The cause of failure is attributed to the

application of glass wool insulation which resulted in the production of chloride ions leading to pitting corrosion and subsequently resulting in pipeline leakage [16]. To address the discrepancies existing between the experimental and analytical results for the plastic collapse failure of pipelines, a different yield criteria based on Tresca and von Misces rule was established. Indicated as average shear stress yield (ASSY) criteria, the results from this new principle were shown to appreciably match with that derived from experiments [17]. Study on development of optimized pipeline network for achieving cost effectiveness and accommodation of potential new networks through numerical techniques was done in a study. The aim of this research was to provide solutions for effective exploitation of natural gas reserves [18]. Time dependent study of hydraulics in a pressurized pipeline system was carried out in an alternative manner along with improvement in calibration methods concerned with pipeline leak detection [19]. Numerical analysis through neural network is proposed for the rational and accurate treatment of non-active supports resulting from the unilateral boundary conditions existing at the pipe vessel interface [20].

Accounting of fluid structure interaction in pipeline system during unsteady flow modelling is becoming viable through the development of relevant numerical and analytical models. In this respect, a detailed review has been presented to cover the essential developments related to this field over the last ten years [21]. In depth assessment and analysis of such interactions is essential in accounting for pressure pulsation in piping systems. For reciprocating compressor piping, one study proposed a comprehensive mathematical method to account for such phenomenon through numerical modelling [22]. The obtained results were further validated through the computational modelling of pressure pulsation and later compared with the past experimental results. In the oil and gas pipeline field site, probability of seismic hazard is generally considered in the analysis. This concern

is addressed through the adoption of uniform confidence method and evaluation of design-basis fault displacements for optimizing the risk analysis of pipeline system [23]. Previously, analytical methods for determining pressure transients in pipeline was limited to utilization of one dimensional model. This was further improved to a twodimensional model method in one research study with the obtained results verified by the relevant conducted http://mc.manuscriptcentral.com/JPME 
experiments [24].

One of the most trending and contemporary approaches dealing with this research subject is based on the software computation and analysis. Due to the considerable saving of man-hours and increased accuracy of results, analysis through commercial software is prevalent in pipe line stress activity. In relation to this fact, a research study highlighting the possible occurrence of computational errors during software analysis is conducted with emphasis laid on the verification of the results through simplified thumb of rules [25].

To further enhance and optimize the computer based piping stress analysis activity, a knowledge based system was proposed and developed for saving substantial amount of time in evaluation and interpretation of obtained results [26]. A pipe line integrity analysis based on the novel computerized techniques local to a pipeline company was developed focusing on the effects of the induction and earth conduction on the structural durability of concerned pipeline system [27]. A numerical analysis of oil slurry transportation through pipeline systems was conducted through utilization of the CFD tools by the application of FLUENT 6.3 software. The obtained results related to the fluid pressure drop were compared with the experimental data and were found to match closely with experimentally determined results [28]. A finite volume method formulation was presented for modelling the transient operation in pipelines transporting steam. The purpose of adopting the specific approach was to

evaluate the characteristic pipeline response during startup, shut down and load variation conditions [29].

Application of commercial software packages such as CAESAR-II for pipeline stress analysis is widely practiced in oil and gas industry. An extensive overview of the working and usage of CAESAR II software for determining stresses in piping systems can be found in literature [30]. Probability of occurrence of natural hazards such as earthquake is often higher in areas where natural gas pipelines of considerable span length are located. This issue was duly addressed through numerical simulation of a pipeline model subjected to similar conditions by CAESAR II software application. Emphasis was laid on the evaluation of the optimum length of suspended pipeline segments for limiting the stresses below the allowable limit [31]. To investigate and accurately demonstrate the effect of vibrational loads on pipeline integrity, a computational stress and vibration analysis of a pipeline system connected to a positive displacement pump was carried out based on CAESAR II software [32].

A related scientific research was developed and presented for reducing the dynamic excitation in the hydraulic pipeline systems with optimizing the hoop positions by finite element method application through ANSYS software [33]. For promoting effective modelling practices in relation to the time dependent pipeline flow characteristics, a conventional finite element method was extended for modelling transient flow in hydraulic pipeline systems [34]. Design considerations relating to the transport of gaseous fluids such as carbon dioxide by pipeline systems was covered through the utilization of ASPEN PLUS software package. The major aim of simulation was to measure pipeline distances facilitating the efficient and safe transfer of carbon dioxide to the booster stations [35]. Pipeline networks constructed for transporting high pressure and high velocity fluids are regularly subjected to time dependent loads and operational variations. An attempt had been made to predict 
the resulting fluid structure interaction through finite element method technique [36].

Testing methods for the strain determination in submarine pipelines are widely well-established and practiced in industry. Owing to the usual appearance of unrealistic test values, a specific research examination of such values was done and compared with the values obtained from the engineering bending theory application through finite element method [37]. To take into consideration the inelastic behavior in long pipeline systems, an elemental methodology termed P3D2HE was formulated in a research study to estimate the pipeline material elastic-plastic response under high shearing forces. The purpose of the conducted research was to predict the potential occurring failure loads through finite element formulation [38]. Recent past years have witnessed the increase in awareness of pipeline integrity management systems and guidelines particularly in oil and gas pipeline companies. A comprehensive review was outlined in a paper with demonstration of IDEF0 functional method for development of relevant activity and life cycle models [39]. Due to nonlinear nature of seismic loading in buried pipelines, a stochastic analysis methodology was outlined in one paper with significant emphasis given to the application of probability density evolution method (PDEM) [40, 41]. Pipeline systems subjected to vibrational loads such as in aircrafts were conventionally designed through one dimensional finite element method. This was further extended to two-dimensional model in one study to account for the fatigue life analysis of aircraft pipeline [42].

Research studies based solely on the experimentally determined results are rare and were often conducted prior to the availability of the recent computational methods and tools. An investigation on the flexibility present in threedimensional pipeline with anchor reactions was carried out with the successful verification of derived results with available design calculations [43]. For enabling economic accommodation of a vacuum flasher in the heat cycle of a Japanese geothermal power plant, an experimental feasibility study was conducted for the realization of pipeline network connecting the wells with the plant site [44]. Effect of roughness occurring in subsea flexible pipeline networks on fluid flow was experimentally analyzed and compared with computational fluid dynamics (CFD) models. The study was aimed towards reviewing the current industrial practices with regards to roughness value selection for low Reynolds number flow [45]. To verify the compatibility of the results related to piping flexibility with analytical calculations, a two-dimensional pipeline model was experimentally analyzed under various loading conditions. The results recorded during experiments agreed with those obtained from calculation method [46].

An effective comparison of the flexibility factors and stresses of piping tees obtained through finite element method was done with the results from experiments conducted by Combustion Engineering Incorporation. The major objective of this study was to determine the effectiveness of proposed finite element methods [47]. During aircraft operation, significant water hammer effects are generated during filling up of pipeline in the propulsion system. To effectively investigate the occurrence of pressure peaks and other transient events, a test bench setup was constructed for obtaining the necessary test results [48]. A research effort concerned with the examination of the vibration effects on pipeline system was made through Pulse6 system. The characteristic natural frequencies and modal shapes of a typical pipeline system were then experimentally determined and compared with a finite http://mc.manuscriptcentral.com/JPME 
element method analysis conducted through Solid Works software [49].

It is observed that there is a distinct lack of a systematic and well developed approach for pipeline flexibility analysis considering both the contemporary computational methods and analytically derived formulations. Methods generally available are specifically inclined towards one of the three

basic analytical approaches as mentioned previously at the start.

\section{Proposed Methodology}

In this paper, both software and analytical tools are perceptively utilized for the provision of an efficient and methodical analytical procedure. The method is aimed towards developing a rational understanding of several design constraints that are involved in a typical pipeline flexibility design problem. The first step involved modelling the pipeline system on CAESAR II software for obtaining the necessary output results in the subsequent stages. Displacement analysis was first conducted to obtain an optimum support span value for the pipeline configuration. This was done through the application of a mathematical equation formulated through engineering mechanics concept. Stress analysis was then conducted to obtain stress distribution diagrams with respect to the nature of occurring stresses. To check the feasibility and effectiveness of the inserted supports, reaction analysis was then carried out. Finally, the structural integrity of the nozzle at each end of pipeline system was verified through checking the local moments and forces with the allowable limits. Each of the four stages of analysis have a pivotal and insightful role in ensuring a safe and efficient design of the pipeline system.

It is pertinent to mention that the loads considered in the analysis are static and internal in nature, i.e. temperature, weight and pressure. Due attention is given to comply with the allowable design limits as set by the concerned codes, standards, industrial practices and client regulations.

\section{Description of Pipeline Model}

Computational modelling of the pipeline for flexibility analysis involves the application of either beam, shell or solid type element [50]. In terms of accuracy, solid type model provides the most reliable results for determining the 3D stress profile of the system. However, the computational effort and time required could be enormous, and thus such element adoption is only preferred for specialized cases. Shell element use is prevalent under situations in which localized stress calculations are required. On the other hand, adoption of 1-D beam element model is considered reasonable if the pipeline length is considerably larger than the diameter value [51]. Several engineering practices validate the adoption of beam model if pipeline diameter-ratio is less than 100 [52, $\underline{53}$. For this reason, CAESAR II was duly utilized for beam modelling since pipeline diameter-ratio is around 38 for the proposed model configuration.

The typical 3D beam element has six permissible degrees of freedom at each node. Furthermore, the element can only be modelled as a bending beam, truss elementand a peam, ynder torsional load. One of the distinctive 
modelling features includes the mesh generation through nodes and evaluation of pipeline behavior only at the provided node locations. This implies that keeping a minimum distance between two adjacent nodes is essential for attaining accurate results. However, this will drastically increase the calculation duration, and therefore a compromise is required by developing a reasonable engineering practice. One of such practices as discussed in [54], recommends that in the case of pipeline diameter exceeding $304.8 \mathrm{~mm}$, the distance between nodes should be kept less than 20 times the pipeline diameter. In all other cases, the node distance should not exceed the value of 30 times the pipeline diameter $[\underline{55}, \underline{36}]$. It is pertinent to mention that pipeline weight forces are assumed to be equally distributed among two adjacent nodes.

A substantial portion of the pipeline model results are based on ASME B31.4 code principles. The stress analysis involved the application of code stress equations for both thermal and primary loads implemented at each node location. These are then compared with their respective

allowable limits as defined by the code [56]. Since all the stress equations and limits are code-based, these can be readily obtained and verified by the relevant code content. Classical beam theory concepts and solid mechanics principles primarily for the piping structure were utilized in developing the displacement equation. The equation serves a key role in determining pipeline span length by taking account of pressure, weight and temperature loading conditions.

All the four components of the flexibility analysis as highlighted in the earlier section are dependent on the loading conditions persisting in the pipeline system. These physical characteristics are in the form of pipeline material weight, pipeline pressure and fluid medium temperature. The occasional loads occurrence due to earthquake, windstorm or snowfall are assumed to be nonexistent. Furthermore, only the design operating conditions of temperature and pressure have been considered owing to their significance to the overall pipeline design process [57]. Ambient conditions of $21^{\circ} \mathrm{C}$ and $100 \mathrm{KPa}$ are assumed for the pipeline model.

\section{Validation of Pipeline Model}

The methodology developed and discussed with reference to specific engineering criteria can be readily associated with the previous research studies on pipeline flexibility analysis. Conceptual application of numerical or computational tools is a common practice since experimental studies in pipeline analysis prove to be expensive and time consuming. A considerable amount of research as highlighted in the literature review section revolves around numerical and software simulation. Moreover, use of commercial software package like CAESAR II is extensive, particularly for stress analysis. This is attributed to the software feature of recognizing code standards in stress calculations and perceptive recommendation of load cases [56]. Application of such software validates the accuracy of the obtained results with respect to the relevant code guidelines.

Pipeline and piping structures collectively constitute the possible system configurations involved in pipe http://mc.manuscriptcentral.com/JPME 
engineering field. As discussed in the introduction section, pipeline analysis is distinctly different from piping analysis owing to numerous reasons. However, the design techniques developed for one structural type can be readily utilized for other type as well. This is clearly demonstrated in various previously conducted research studies. In this respect, a similar overall design approach as outlined in this paper had already been implemented for a heat exchanger piping system [10]. A different set of design codes and standards were utilized for analysis in that study.

One of the major objectives of this work is the provision of a unified and flexible perspective of design analysis of piping and pipeline systems alike. The necessary credibility associated with the design procedure is assured through compliance with standardized and relevant engineering standards and practices. In addition, the software and numerical tools employed are derived and distinctly connected with the available established literature. It is intended that a complete spectrum of piping system analysis be covered by elaborating the proposed methodology for a typical pipeline system.

Further reaffirmation of the pipeline span length result can be sought from the relevant engineering convention as mentioned in [58]. As per the design rule expressed in feet length units, pipe support spacing for steel pipe with liquid medium service can be taken as the nominal pipe size (in inches) added with ten. For this model, the value comes out to be 14 feet or around $4.3 \mathrm{~m}$. The additional relevant contribution of pressure and temperature implies a lower span value than the recommended one. It will be seen later in the displacement analysis section that the pipe span length is indeed lesser than the above obtained value.

Table 1. System design operating conditions.

Condition

\begin{tabular}{ccc}
\hline Design & 10,000 & $\mathrm{kP}$ \\
Pressure & & $\mathrm{a}$ \\
\hline
\end{tabular}

Operating

Value Unit

Displacement X-

Y-

Z-
Table 2. Maximum allowable pipeline displacement.

\begin{tabular}{cccc} 
& Direction & Direction & Direction \\
\hline Allowable Value & $\pm 0.5 \mathrm{~mm}-$ & $\pm 0.2 \mathrm{~mm}$ & $\pm 0.5 \mathrm{~mm}$ \\
& & & -
\end{tabular}

\footnotetext{
Design Temperature

23

${ }^{\circ} \mathrm{C}$

$\pm 0.7 \mathrm{~mm}$

$\pm 0.7 \mathrm{~mm}$
}

in the system was realized by each of the three sub parts in 


\section{Theory/Calculation}

\subsection{Model design specification}

the equation, as indicated in Eqs. 1 and 2 [60, 61].

$$
Y=Y_{\text {weight }}+Y_{\text {pressure }}+Y_{\text {temperature }}
$$

To commence the analysis demonstration, initially the pipeline system was modelled through the CAESAR-II soft-

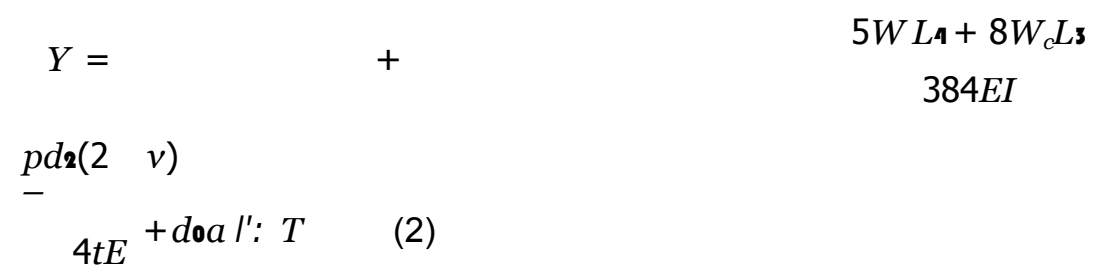

ware. This was done keeping in view the available isometric drawings and prevailing design operating conditions. The pipeline system serves to transport crude oil between the two storage facilities. Lighter fraction of crude oil with API gravity higher than $31.1^{\circ} \mathrm{API}$ was considered as a fluid transporting medium. Fig.1 displays the isometric drawing of the pipeline configuration as obtained through initial software modelling. Table 1 summarizes the design operat- ing conditions occurring in the entire system. The pipeline material selected for the entire system is a carbon steel grade with specification as API-5L X42. It is particularly suited for applications requiring transport of medium to high pressure fluids over long pipeline distances.

\subsection{Displacement Analysis}

Values of maximum permissible displacements for all three directions were provided by the client. The instructed allowable limits serve as an additional design constraint apart from those provided by the ASME B31.4 design code. An identical practice of complying with the client regulations was highlighted in a related scientific study [59]. Table 2 highlights the allowable displacement limits specified for all three directions. Application of mathematical equation derived from the conceptual implications of classical beam theory was utilized for support span calculation. The contribution of each of the three loading conditions present

The first equation component is derived by considering the action of weight of pipe, insulation and fluid as a uniform force acting over the pipeline length alongwith concentrated force arising due to flanges and valves. The second part accounts for the net pressure forces exerted by the fluid in circumferential direction. The last component considers the pipe expansion in radial direction due to temperature difference with the surroundings.

Relevant recording of values of term as required for the above equation application was done and summarized as below. Total weight of piping and fluid was calculated through CAESAR-II during design modelling.

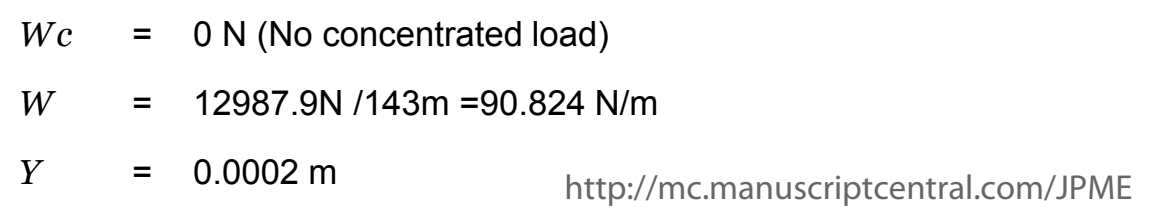


$O$

$$
\begin{array}{ll}
E_{i} & =2.0325 \times 10 ı \mathrm{~Pa}[\underline{62}] \\
I=\left(\pi d_{\boldsymbol{\imath}}\right. & \left.-\pi d_{\mathbf{\imath}}\right) / 64=1.64939 \times 10^{-} \bullet \mathrm{m}^{\uparrow} \\
a \Delta T & =0.000021 \mathrm{~m} / \mathrm{m} \mathrm{[62]} \\
v & =0.300 \\
d_{i} & =0.108204 \mathrm{~m} \\
d_{o} & =0.1143 \mathrm{~m} \\
p & =10,000,000 \mathrm{~Pa} \text { (design } \\
t & =0.003048 \mathrm{~m}
\end{array}
$$

\subsection{Stress Analysis}

Like plant piping [63], stresses encountered in pipeline trans- portation systems for hydrocarbon liquids are categorized as

either primary or secondary stresses. Primary stresses are characterized by their non-self-limiting nature and results from the sustained type loadings such as weight and pressure. Secondary stresses are generated due to the range of temper- ature variation occurring from plant startup or shut down and other cyclic loadings of similar nature.

6.3.1 Existing primary stress criteria: As directed by the ASME B31.4 code [62], three major design criteria exist for evaluating unrestrained pipeline safety against primary loadings:

1. Wall thickness of pipeline section shall be equal to or greater than the minimum allowable thickness limit as stated by Eq. 3 below [62].

\section{$P D$}

\subsection{Reaction Analysis}

For evaluation of structural integrity of supports, distinct and well defined design guidelines are mentioned in ASME B31.4 [62]. As per the set rules, tensile stresses occurring in structural supports must not exceed $66 \%$ of the material minimum yield strength. Similar allowable limit is also applicable for compressive stress values. Stresses in bearing and shear have permissible limits of $0.49 S_{y}$ and $0.90 S_{y}$ respectively. In this paper, scope of the reaction analysis will be limited to the determination of the potential rest support locations where zero reaction force occurs. Removal of such supports from the final model will lead to the realization of economic and efficient support layout configuration in this pipeline system.

$$
t_{m}=
$$




\subsection{Nozzle Analysis}

1. Allowable hoop stresses resulting from the internal pressure forces shall primarily be based on the yield strength as given by Eq. 4 [62].

$$
S_{h} \leq 0.72 e S_{y}
$$

2. Longitudinal stresses due to the sustained pipeline loads must comply with the allowable stress limit as described by

$$
S_{L} \leq 0.75 e S_{y}
$$

6.3.2 Criteria for secondary stresses: For stresses occurring due to cyclic loads, ASME B31.4 [62] specifies a design limit as shown in Eq. 6 [62].

$$
S_{E} \leq S_{A}
$$

$S_{E}$ in Eq. 6 is an expansion range stress developing because of pipeline being subjected to temperature change during start up or shutdown condition. $S_{A}$ is the allowable stress limit through which these secondary stresses are compared.

Nozzle serves the crucial function of connecting the pipeline network with the adjoining equipment often located at remote locations [64]. In the pipeline model under consideration, one nozzle is located at each end of pipeline connected to a storage vessel. Allowable limits of forces and moments are based on a relevant industrial practice attained from reliable experiences of pipe stress community [65]. For nozzle size falling under range of 4 inch to 16 inch, allowable forces and moments can be regarded as being equal to $250 \mathrm{D}$ and 300D respectively. $\mathrm{D}$ denotes the diameter of nozzle in inches.

\section{Results and Discussion}

\subsection{Results from displacement analysis}

After application of the mathematical equation discussed in the previous section, the value of span length for which the downward displacement limit is satisfied is coming out as $2.40122 \mathrm{~m}$. Based on this value, rest supports were then inserted and modelled in the software.

As previously mentioned in the pipeline model section, the permissible node distance should not exceed 30 times the pipeline diameter value. In this respect, it must be noted that the pipeline span length indicates the largest 
allowable nodal span. This distance equals to $3.429 \mathrm{~m}$ for a 4inch nominal diameter which is greater than the obtained span value. It is thus verified that the nodal mesh generation is rational and valid for the model.

After running the static analysis for the model, excessive displacements in $x$ and $z$ direction were then noted. Fig. 2 shows the locations in pipeline experiencing excessive axial displacements. Displacements in z direction were coming out to be zero at all locations. Fig. 3 shows the final support configuration layout limiting the displacements to allowable limits in all three directions. Displacement bar charts as shown in Fig. 4 serve to summarize the displacements occurring at each node in all three direction.

It is pertinent to outline the methodology adopted for the selection of the optimum location of supports. Loads arising due to weight are uniform in nature and the resulting deflection can therefore be readily expressed through a mathematical equation. In the similar way, mathematical formulation for downwards deflection due to pressure and temperature loads can be devised owing to their uniform and linear nature. In this manner, it was found convenient to specifically utilize Eq. 2 for calculation of maximum support span. Extensive analytical working was needed for following a similar approach for limiting other displacements, thus leading to increasing complexity and loss of productivity in analysis. Software analysis was thus utilized for specifically noting the locations where displacements are above the allowable limits. Thus, guide support was then strategically inserted on the vertical pipeline run for restricting the axial displacements below the recommended value. As indicated through Fig. 4, successful verification of the analytical result for span support was also achieved.

7.1.1 Detail of loads contribution to $X$ direction displace- ment Fig. 5 below represents the composition distribution of $X$ displacement resulting from sustained and thermal loads. More than $99 \%$ of displacement contribution is attributed to the thermal expansion loads. The thermal displacements are most pronounced at the vicinity of the pipeline bend region due to the movement limitation imposed by the guide restraint and nozzle connection at the vertical pipe run. This leads to the transfer of significant thermal movements to the pipeline straight run length. On the contrary, the primary loads effect on $\mathrm{X}$ displacement is negligible throughout the pipeline length.

Further examination of primary component of $X$ displacement was carried out. The major objective was to obtain the relative significance of the weight and pressure loads in terms of their input to displacement. Fig. 6 summarizes the obtained results in the form of the pie chart. More than $95 \%$ of displacement input is provided by the weight force while the pressure load accounts for only a small portion. One of the major reasons for such little primary load contribution to overall displacement can be associated with this result. Weight loads, owing to their vertical direction, do not substantially influence the horizontal displacement. Since they are more dominant than the pressure loads, the overall influence on the displacement is drastically small.

Further investigation was conducted on applied primary loads to determine the pressure condition leading to an appreciable change in displacement. For this purpose, a test model was developed in which all other physical characteristics except for pressure were kept constant. It was observed that pressure influence becomes notable only after it is increased by 100 times the original value. Therefore, it can be reasonably concluded that for a similar http://mc.manuscriptcentral.com/JPME 
type of pipeline systems, the pressure contribution to the lateral displacements remains negligible. Fig. 7 displays

the displacement composition results obtained from the test model.

7.1.2 Detail of loads contribution to $Y$ direction dis- placement The similar analytical procedure as above was adopted to sub divide the overall $Y$ displacement in terms of occurring loads. Fig. 8 shows the percentage distribution of $Y$ direction displacement. It can be observed that this time the effect of sustained loads is substantially greater than the persisting thermal loading conditions. Owing to the pipeline and fluid medium weight, the load contribution from primary loads is greatest at the straight parallel run of the pipeline. It gradually diminishes near the bend region relative to thermal loads due to the emergence of appreciable thermal movement from the vertical pipeline run. Due to the presence of guide restraint and outlet nozzle connection, appreciable thermal displacements near bend region occur in the $\mathrm{Y}$ direction.

Subdivision of the primary part of $Y$ displacement was done as the next step. Fig. 9 shows the weightage of weight and pressure effects on the primary displacement. It can be seen that the pressure effect on the $Y$ displacement is negligible as compared to the weight. The primary part of displacement is totally dominated by weight loads throughout the length of the pipeline. This can be directly linked to the direction and uniform nature of the weight forces occurring due to the pipeline material and fluid medium.

Test model results for the primary part of $Y$ displacement were also explored. Despite an immense increase in the internal pressure value, the pressure contribution percentage rises to only $1.2 \%$. It can thus be inferred that the similar pipeline systems will be overwhelmingly influenced by weight forces with respect to the occurring $Y$ displacement. Fig. 10 describes the displacement distribution in term of sustained loads for the test model.

\subsection{Results from Stress Analysis}

7.2.1 Wall thickness criteria result: After calculating the value of minimum wall thickness through Eq. 3, it was then compared with the actual wall thickness value. $t_{m}$ was calculated as being approximately $2.74 \mathrm{~mm}$ while the actual pipeline wall thickness selected for the model was around $3.0480 \mathrm{~mm}$. It can thus be inferred that the model passes the first criteria.

7.2.2 Hoop stress compliance criteria: The calculated hoop stress for the model was recorded to be 187.5 MPa. This was comparatively lesser than the allowable limit value, which was computed to be around $290 \mathrm{MPa}$.

It is imperative to note that the formula used for hoop stress calculation is the standard one that is readily obtainable from existing literature and also recommended by ASME B31.4.

7.2.3 Longitudinal stress compliance criteria: Stress distribution diagram was obtained for the longitudinal stresses through CAESAR-II software. It was observed that the highest stress percentage was around $56 \%$ occurring at the 
location as shown in Fig. 11.

The peak stress location is in close proximity to the pipeline bend component. It is expected that higher sustained stresses will occur in such region due to the bourdon effect influence on pipeline elbow [66]. Possibility of bend ovalization can lead to higher induced stresses on the nearby straight piping due to the difference between the inner and outer pipe cross-section. It is therefore necessary to specifically pinpoint such locations to ensure pipeline functionality with respect to primary stresses.

Primary stress effects were further studied to determine the significance of component loads. The composition division in terms of weight and pressure influence can be observed in Fig. 12. The role of weight loads in the overall stress profile is quite trivial as compared with the internal pressure forces. Insertion of rest supports at regular pipe

length interval prevent the bending stresses from weight to rise appreciably. On the other hand, longitudinal pressure stresses are prominent due to extensive horizontal pipeline run which serves to accumulate the pressure contribution per pipeline length.

Corresponding highest values of longitudinal and allow- able stresses were recorded as $87.9 \mathrm{MPa}$ and $156.37 \mathrm{MPa}$ respectively. The obtained results affirm the system safety against the occurrence of primary loads such as weight and pressure.

7.2.4 Expansion stress compliance criteria: Analysis and determination of thermal stresses was also conducted through CAESAR-II software. Fig. 13 displays the stress distribution diagram obtained for this stress type along with the location of peak stress occurrence. Highest percentage of stress was observed to be around $22 \%$ occurring at the guide support location.

The guide restraint serves to limit the pipeline lateral displacements to ensure compliance with the allowable limits. As a result, the thermal movement is considerably restricted near the vertical pipe length section, resulting in higher local thermal stresses. For the horizontal pipeline section, thermal stresses are remarkably lower and tend to gradually increase near the pipeline elbow region. This can be attributed to sufficient provision of thermal movement due to pipeline horizontal geometry. Such characteristic feature is also evident from the $\mathrm{X}$ displacement composition results obtained earlier. Thermal displacements account for more than $90 \%$ of total value and consequently leads to lower stress occurrence.

Values of maximum expansion stress and the correspond- ing allowable limit were obtained to be $45.36 \mathrm{MPa}$ and 208.49 MPa respectively. The computed results imply that the system is secure against stresses resulting from tempera- ture variations and other cyclic loadings.

\subsection{Results from Reaction Analysis}

Due to the deflection, possibility of pipeline lifting from rest supportscanpattbe overlooked. This eventually leads to 
the zero-reaction force at some rest supports. The focus of this analysis was to either ensure the removal of extra unnecessary supports or readjust the support configuration for achieving cost saving and efficient load distribution.

Fig. 14 shows the utilized rest supports in the pipeline system. It can be observed that all the supports were indicated to be functional through the restraint symbol notation. The total number of supports used in the model amounts to 60 . One guide support and 59 rest supports were inserted to ensure pipeline functionality with respect to displacement, stress and reaction analysis.

Further insightful studies depicting the reaction force configuration was conducted with reference to primary and secondary loads. Majority of the rest supports on the horizontal pipeline length experienced a similar load magnitude. The rest supports in the bend region vicinity registered a steady load increase as the last rest support location was approached. The support at this location had the greatest vertical reaction force exerted by the pipeline system.

Further analysis revealed the reason for such increase to be associated with the thermal movement transfer from pipeline elbow and vertical pipe run. This is also manifested through comparatively higher reaction load on the guide restraint. Furthermore, the last rest support technically also supports the weight of the adjacent vertical pipe run.

The vastly similar load magnitude of the rest supports result from the action of uniform sustained loads occurring along the pipeline length. Among those loads, the weight contribution is strikingly higher at all node locations.

\subsection{Results from Nozzle Analysis}

After reaction analysis, the final check relating to the nozzle structural integrity was conducted. It is pertinent to describe

the local coordinate axis system on which the loads and moments are based upon. CAESAR II make use of $A B C$ coordinate system [56], defined as follows:

A - Axis of nozzle.

$B$ - Axis along the equipment axial direction. $C$ - Axis perpendicular to $A$ and $B$.

Summary of the comparison of actual occurring loads and moments with their allowable respective limits is given by Table 3.

Table 3. Comparison of actual and allowable nozzle loads

extremely critical when high thermal displacements are involved.

Influence of primary loads was also considered in this analysis. A similar trend was observed with regards to the comparative contribution of weight and pressure forces. Pressure conditions have a minor effect on the nozzle load magnitude for both inlet and outlet ends. Weight effects, although not as pronounced as the thermal counterpart, are significantly dominant than the pressure effects for both nozzles ends. 
Forces and

Inlet Nozzle (N1)

Outlet Nozzle (N2)

\section{Conclusion}

\begin{tabular}{|c|c|c|c|c|}
\hline Moments & Allowable \pm & Actual & Allowable \pm & Actual \\
\hline$F_{a}(\mathrm{~N})$ & 4448 & -3768 & $\begin{array}{c}444 \\
8\end{array}$ & 1781 \\
\hline$F_{b}(\mathrm{~N})$ & 4448 & -109 & $\begin{array}{c}444 \\
8\end{array}$ & -3575 \\
\hline$F_{c}(\mathrm{~N})$ & 4448 & 0 & $\begin{array}{c}444 \\
8\end{array}$ & 0 \\
\hline$M_{a}(\mathrm{Nm})$ & 1626 & 0 & $\begin{array}{c}162 \\
6\end{array}$ & 0 \\
\hline$M_{b}(\mathrm{Nm})$ & 1626 & 0 & $\begin{array}{c}162 \\
6\end{array}$ & 0 \\
\hline$M_{c}(\mathrm{Nm})$ & 1626 & -44 & $\begin{array}{c}162 \\
6\end{array}$ & 481 \\
\hline
\end{tabular}

Results from the above table clearly indicates that both the nozzles have passed the design criteria as set by the industrial practice used for pipeline stress analysis activity in design companies.

In addition to displaying compliance with the allowable limits, the table results highlight some significant features regarding the local nozzle loads. For the inlet nozzle, the highest load occurs in pipeline axial direction. On the contrary, the outlet nozzle has the highest load component in the equipment axis direction. Further inspection of such feature revealed the underlying reason to be directly linked with the axial thermal displacement ( $X$ direction) distribution. These displacements, being highest near the pipeline bend region, substantially contributes to the load exerted by the pipeline system on the two nozzles.

For the inlet nozzle, such an influence is manifested axially while this effect is most pronounced in a lateral direction relative to outlet nozzle orientation. Nozzle location allows only for limited freedom of movement and are This paper addresses the flexibility analysis considerations in pipeline system through the provision of a wellstructured and systematic scientific method. Application of relevant contemporary practices in combination with the utilization of well-established principles were done for devising a novel and efficient design procedure. Due recognition was given to the limits specified by the applicable codes and industrial practices. On this basis, the location and selection of supports was finalized through the results obtained from displacement, stress, reaction and nozzle analysis. The methodology proposed in this paper can readily be adapted and applied to any pipeline system.

Apart from providing an organized strategy, this study will also contribute towards time saving practices during pipeline stress activity. Previous conventional studies extensively relied on either software or numerical tools, resulting in laborious and inefficient procedure development. While such methods were practically applicable for specific piping systems, much greater detail and depth were needed for generalizing their application to account for a diverse set of constraints. In pipe stress industry, this will result in frequent modification of the established SOP 
(standard operating procedure) regarding the analytical procedure. Such changes will markedly hinder the routine working cycle, leading to poor and mismatched coordination among the stress

engineers. Furthermore, adoption of a single analytical tool such as manual formulae leads to increased complexity which is usually not feasible as an industrial practice. It is imperative for any stress engineer in the industry to be quickly acquainted with the established stress procedure to avoid the occurrence of any discrepancy between obtained results.

It is, therefore, necessary that a robust and concise analytical approach is readily available for pipe stress design activity. In addition, a clearer understanding of the underlying concepts will lead to smoother work flow and quicker completion of stress analysis tasks. The methodology developed in this paper is derived from simplified concepts discussed extensively in available pipe stress literature. Moreover, the systematic flow assures the stepwise application of each result for the next analytical stage. The validity of the method is assured through adherence to the relevant codes and standards.

Although CAESAR II application is common in flexibility analysis, the suggested approach ensures its sequential and conceptual utilization, integrating it well with the applied numerical methodology. Various aspects of this method can be readily adapted for analyzing different pipeline configurations. It is firmly believed that adoption of this technique will result in quicker familiarization with the design solution, resulting in lesser lead time for generation of stress isometrics as a final component of stress design activity.

The future work may extend the proposed method to account for the effect of the occasional loads occurring in a similar pipeline system.

\section{References}

[1] Industrial development for the 21st century: Sustain- able development perspectives. Technical report, Department of Economic and Social Affairs of the United Nations Secretariat, 2007.

[2] Transportation of hazardous liquids by pipeline; Code of Federal Regulations, Title 49, Part 195, 2017.

[3] Transportation of natural and other gas by pipeline: Minimum Federal Safety Standards; Code of Federal Regulations, Title 49, Part 192, 2017.

[4] Bahadori A. Oil and Gas Pipelines and Piping Systems: Design, Construction, Management, and Inspection. Elsevier, 2017.

[5] Menon ES. Transmission Pipeline Calculations and Simulations Manual. Elsevier, 2015.

[6] Stephenson D. Pipeline design for water engineers.

Developments in Water Science 1981; 15: 27-52.

[7] Peng LC. Stress analysis methods for underground pipe linesp Technical report, AAA Technology and 
Specialities Co., Inc., Houston, 1978.

[8] Li G, Hua B and Liu Bea. Study for flexibility analysis method in heat exchangers network. In Tsatsaronis G (ed.) The Second Biennial European Joint Conference on Engineering Systems Design and Analysis, 1994, volume 1. London: American Society of Mechanical Engineers.

[9] Bhende $G$ and Tembhare G. Stress intensification and flexibility in pipe stress analysis. International Journal of Modern Engineering Research 2013; 3(3): 1324- 1329.

[10] Zahid U, Khan SZ, Khan MA et al. A methodology for flexibility analysis of process piping. Proceedings of the Institution of Mechanical Engineers, Part E: Journal of Process Mechanical Engineering 2017; .

[11] Boyle JT. Design \& analysis of piping systems - a short course. University of Strathdyde, Glasgow, UK.

[12] Abharya K, Nourbakhshb A and Lounga L. An exact analytical method for stress analysis of pipelines.

International Journal of Pressure Vessels and Piping

1999; 76(8): 561-565.

[13] Rossheim D and Markl A. The significance of, and suggested limits for, the stress in pipe lines due to the combined effects of pressure and expansion. Transactions of the ASME 1940; 62(5): 443-460.

[14] Poynor JF. Dead-weight stresses in piping systems and their inclusion in thermal stress analyses. Proceedings of the Institution of Mechanical Engineers, Part E: Journal of Process Mechanical Engineering 1958; 172(1): 513-530.

[15] Mazzola A. Thermal interaction analysis in pipeline systems a case study. Journal of Loss Prevention in the Process Industries 1999; 12(6): 495-505.

[16] Kumar MS, Sujata M, Venkataswamy M et al. Failure analysis of a stainless steel pipeline. Engineering Failure Analysis 2008; 15(5): 497-504.

[17] Zhu XK and Leis BN. Average shear stress yield criterion and its application to plastic collapse analysis of pipelines. International Journal of Pressure Vessels and Piping 2006; 83(9): 663-671.

[18] Rothfarb B, Frank H, Rosenbaum DM et al. Optimal design of offshore natural-gas pipeline systems. Operations Research 1970; 18(6): 992-1020.

[19] Kim SH, Yoo WS, Oh KJ et al. Transient analysis and leakage detection algorithm using GA and HS algorithm for a pipeline system. Journal of Mechanical Science and Technology 2006; 20(3): 426-434.

[20] Baniotopoulos C. Analysis of above-ground pipelines on unilateral supports: a neural network approach. International Journal of Pressure Vessels and Piping 1998; 75: 43-48. 
[21] Wiggert DC and Tijsseling AS. Fluid transients and fluid-structure interaction in flexible liquid-filled piping. Applied Mechanics Reviews 2001; 54(5): 455-

481.

[22] Zhan L and Duan Z. Development of a transient gas dynamic model for the simulation of pulsation in reciprocating compressor piping systems. Proceedings of the Institution of Mechanical Engineers, Part E: Journal of Process Mechanical Engineering 2017; : $095440891773758 D O I: 10.1177 / 0954408917737586$.

[23] Liu A, Chen $\mathrm{K}$ and $\mathrm{Wu} \mathrm{J}$. State of art of seismic design and seismic hazard analysis for oil and gas pipeline system. Earthquake Science 2010; 23(3): 259-263.

[24] Nathan GK, Tan JK and Ng KC. Two-dimensional analysis of pressure transients in pipelines. Interna- tional Journal for Numerical Methods in Fluids 1988; 8(3): 339-349.

[25] Peng L. The art of checking pipe stress computer programs. In Truong QN, Goodling EC, Balaschak JJ et al. (eds.) Design and Analysis of Piping and Components, ASME Pressure Vessels and Piping Conference, 1989, volume 169. Honolulu, Hawaii,, pp. 77-83.

[26] Rodriguez-Toral AM and Rosas Mea. Decision-making on pipe stress analysis enabled by knowledge-based systems. Knowledge and Information Systems 2007; 12(2): 255-278.

[27] Dawalibi F and Pinho A. Computerized analysis of power systems and pipelines proximity effects. IEEE Transactions on Power Delivery 1986; 1(2): 40-48.

[28] Zambrano H, Sigalotti LDG, Klapp J et al. Heavy oil slurry transportation through horizontal pipelines: experiments and cfd simulations. International Journal of Multiphase Flow 2017; 91: 130-141.

[29] Taler D and Kaczmarski K. A numerical model of steam pipeline. Procedia Engineering 2016; 157: $158-162$.

[30] Bisht S and Jahan F. An overview on pipe design using Caesar II. International Journal on Emerging Technologies 2014; 5(2): 114-118.

[31] Shang B, Li C, et al. Stress analysis of suspended gas pipeline segment. Journal of Pipeline Systems Engineering and Practice 2017; 8(3): 04017003. 
[32] Lu H, Huang K and Wu S. Vibration and stress analyses of positive displacement pump pipeline systems in oil transportation stations. Journal of Pipeline Systems Engineering and Practice 2016; 7(1).

[33] Zhangchun T, Zhenzhou L, Dawei L et al. Optimal design of the positions of the hoops for a hydraulic pipelines system. Nuclear Engineering and Design 2011; 241: 4840-4855.

[34] Taylor SEM, Johnston DN and Longmore DK. Modelling of transient flow in hydraulic pipelines. Proceedings of the Institution of Mechanical Engineers, Part I: Journal of Systems and Control Engineering 1997; 211(6): 447455.

[35] Witkowski A, Majkut $M$ and Rulik S. Analysis of pipeline transportation systems for carbon dioxide sequestration. Archives of Thermodynamics 2014; 35(1): 117-140.

[36] Sreejith B, Jayaraj K, Ganesan N et al. Finite element

analysis of fluid-structure interaction in pipeline

systems. Nuclear Engineering and Design 2004;

227(3): 313-322.

[37] Guarracino F, Fraldi M and Giordano A. Analysis of testing methods of pipelines for limit state design. Applied Ocean Research 2008; 30(4): 297-304.

[38] Nowzartash F and Mohareb M. An elasto-plastic finite element for steel pipelines. International Journal of Pressure Vessels and Piping 2004; 81(12): 919-930.

[39] Kishawy HA and Gabbar HA. Review of pipeline integrity management practices. International Journal of Pressure Vessels and Piping 2010; 87(7): 373-380.

[40] Liu W, Sun Q and Li J. Stochastic nonlinear analysis for seismic performance of buried pipeline systems. In Second International Conference on Vulnerability and Risk Analysis and Management (ICVRAM) and the Sixth International Symposium on Uncertainty, Modeling, and Analysis (ISUMA), 2014. Liverpool, UK.

[41] Liu W, Sun Q, Miao H et al. Nonlinear stochastic seismic analysis of buried pipeline systems. Soil Dynamics and Earthquake Engineering 2015; 74: 69- 78.

[42] Ouyang P, Gao F, Yang HY et al. Two-dimensional stress analysis of the aircraft hydraulic system pipeline. Proceedings of the Institution of Mechanical Engineers, Part G: Journal of Aerospace Engineering 2011; 226(5): 532-539.

[43] Smith RT and Ford H. Experiments on pipelines and pipe bends subjected to three-dimensional loading. Proceedings of the Institution of Mechanical Engineers, Part C: Journal of Mechanical Engineering Science 1967; 9(2): 124-137.

[44] Takahashi Y, Hayashida T, Soezima S et al. An experiment on pipeline transportation of steam-water mixtures

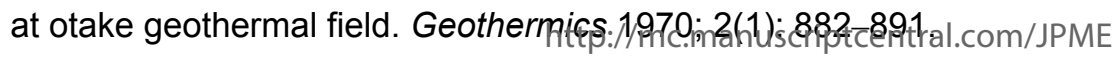


[45] Yin S, Leggoe J, Teng D et al. Experimentation and computational fluid dynamics modelling of roughness effects in flexible pipelines. 2014 CEED Seminar Proceedings, Australia.

[46] Smith RT and Ford H. Experimental study of the flexibility of a full-scale two-dimensional steam pipeline. Proceedings of the Institution of Mechanical Engineers, Part C: Journal of Mechanical Engineering Science 1962; 4(3): 270-286.

[47] Quezon AJ and Everstine GC. Comparison of finite element analyses of a piping tee using nastran and cortes/sa. In NASA. Kennedy Space Center 9th NASTRAN (R) Users' Colloqium. 19800025287, Naval Ship Research and Development Center; Bethesda, MD., United States, pp. 224-242.

[48] Bombardieri C, Traudt T and Manfletti C. Experi- mental and numerical analysis of water hammer during the filling process of pipelines. In Space Propulsion Conference, 2014. Cologne, Germany.

[49] Schrotter M, Trebuna F, Hagara M et al. Methodology for experimental analysis of pipeline system vibration. Procedia Engineering 2012; 48: 613-620.

[50] I-DEAS. Which element type should I use for finite element simulation?, 2012.

[51] Zhao Y, Feng J, Zhao B et al. Vibration analysis and control of a screw compressor outlet piping system. Proceedings of the Institution of Mechanical Engineers, Part E: Journal of Process Mechanical Engineering 2018; : 095440891876356DOI:10.1177/ 0954408918763561.

[52] Wu X, Lu H, Huang K et al. Frequency spectrum method-based stress analysis for oil pipelines in earthquake disaster areas.

PLOS ONE 2015; 10(2):

e0115299. DOI:10.1371/journal.pone.0115299.

[53] $\mathrm{Wu} \mathrm{X,} \mathrm{Lu} \mathrm{H}$ and $\mathrm{Wu}$ S. Stress analysis of parallel oil and gas steel pipelines in inclined tunnels. SpringerPlus 2015; 4(1). DOI:10.1186/ s40064-015-1453-1.

[54] Jiang $X$, Wang $T$, Sun $L$ et al. Stress analysis of unburied gas pipelines laid in high slopes. Natural Gas and Oil 2013; 31: 26-30. 
[55] Zhou Z and Murray D. Analysis of postbuckling behavior of line pipe subjected to combined loads. International Journal of Solids and Structures 1995; 32(20): 3015-3036. DOI:10.1016/0020-7683(94) 00261-t.

[56] Intergraph. CAESAR // 2013 R1 User Guide. Intergraph, 2013.

[57] Alkazraji D. A Quick Guide to Pipeline Engineering.

Woodhead publishing ed. 2008.

[58] Antaki GA. Piping and Pipeline Engineering: Design, Construction, Maintenance, Integrity, and Repair. Marcel Dekker, 2005. ISBN 0-8247-0964-0.

[59] Shehadeh B, Ranganathan S and Abed F. Optimization of piping expansion loops using ASME B31.3. Proceedings of the Institution of Mechanical Engineers, Part E: Journal of Process Mechanical Engineering 2014; 230(1): 56-64.

[60] Beer F, Johnston E and DeWolf J. Mechanics of Materials. Mc-Graw Hill, 2001.

[61] Hearn E. Mechanics of Materials. Butterworth- Heinemann, 1985.

[62] ASME Code B31.4. Pipeline transportation systems for liquids and slurries, 2012.

[63] ASME Code B31.3, Process piping, 2006.

[64] Antaki GA. Analytical considerations in the code qualification of piping systems. In ASME Pressure Vessels \& Piping Conference, 1995. Honolulu, USA.

[65] Nozzle loads (thread292-129476), 2017. URL http://www.eng-tips.com/viewthread. cfm?qid=129476.

[66] Abdulhameed D, Adeeb S, Cheng R et al. The influence of the bourdon effect on pipe elbow. In Volume 3: Operations, Monitoring and Maintenance; Materials and Joining. ASME. DOI:10.1115/ipc2016-64659. 


\section{List of Figures}

Figure 1: Isometric layout of the pipeline system.

Figure 2: Excessive axial displacements and rest supports configuration in model

Figure 3: Final support layout for pipeline model

Figure 4: Displacements occurring in $\mathrm{x}$ and $\mathrm{y}$ direction

Figure 5: Pie chart representation of the $\mathrm{X}$ direction displacement

Figure 6: Pie chart representation of the primary $\mathrm{X}$ direction displacement

Figure 7: Pie chart representation of the primary $\mathrm{X}$ direction displacement (test model)

Figure 8: Y direction composition pie chart

Figure 9: Pie chart display of subdivision of the primary part of Y displacement

Figure 10: Pie chart representing the composition of primary Y displacement (test model)

Figure 11: Longitudinal stress distribution diagram

Figure 12: Pie chart representation of load primary stress contribution

Figure 13: Thermal expansion stress distribution diagram

Figure 14: Feasibility of supports used in the pipeline model 


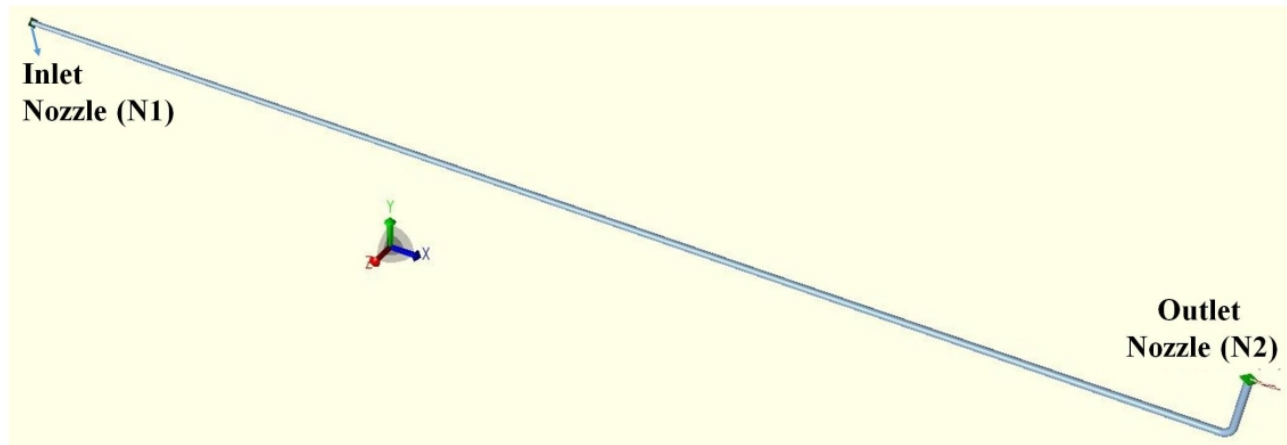

Figure 1. Isometric layout of the pipeline system.

$358 \times 126 \mathrm{~mm}(150 \times 150 \mathrm{DPI})$ 


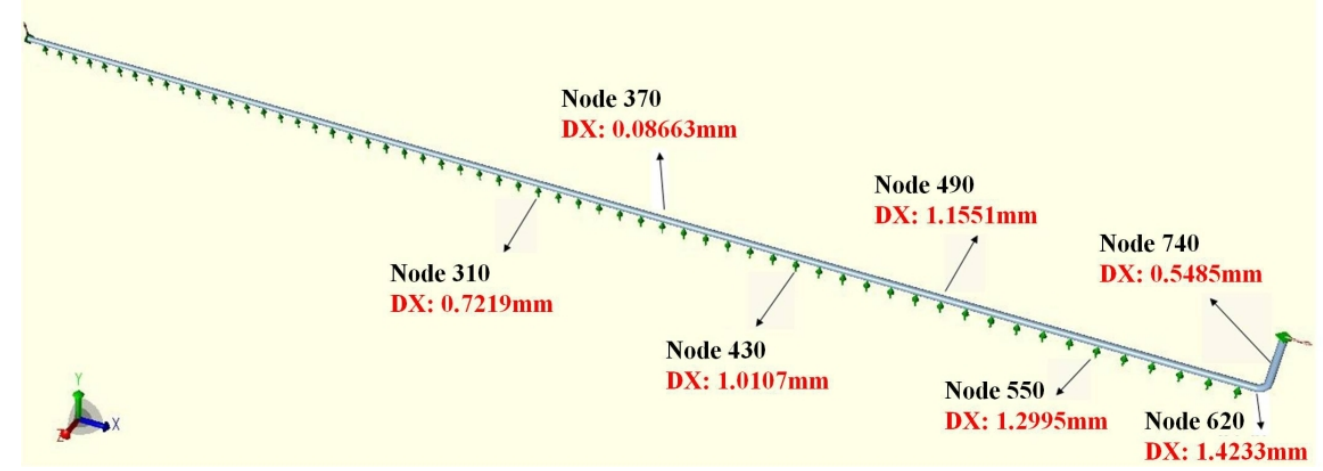

Figure 2. Excessive axial displacements and rest supports configuration in model $360 \times 144 \mathrm{~mm}(150 \times 150 \mathrm{DPI})$ 


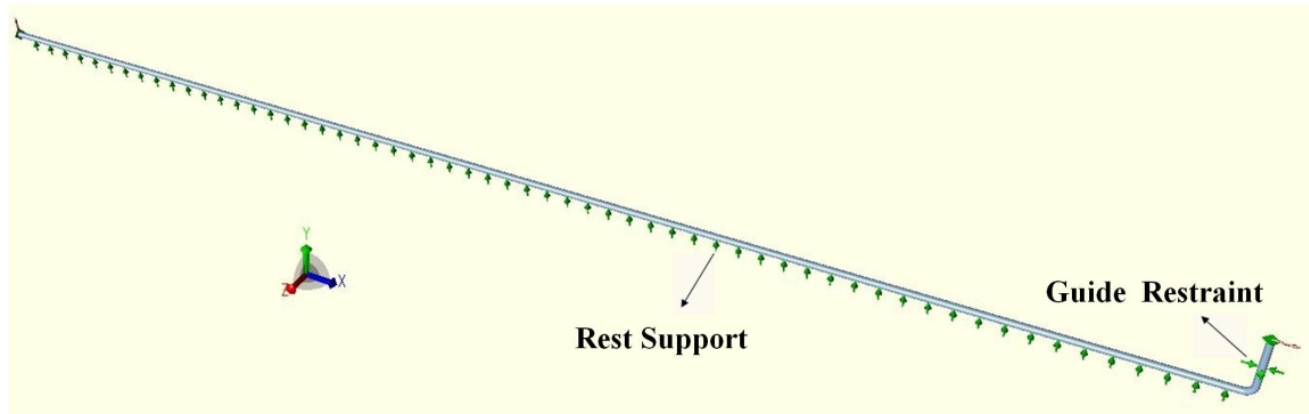

Figure 3. Final support layout for pipeline model $358 \times 114 \mathrm{~mm}(150 \times 150 \mathrm{DPI})$ 


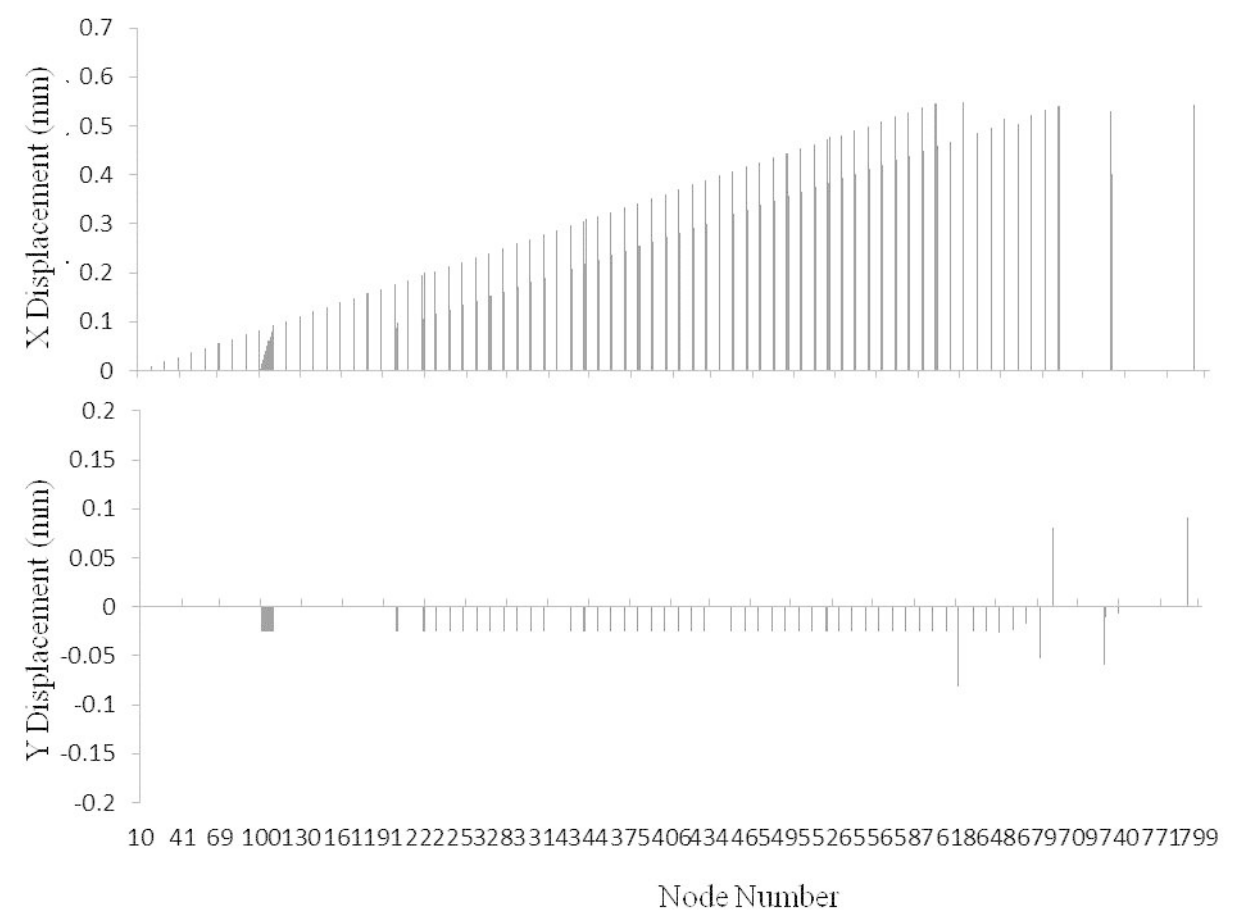

Figure 4. Displacements occurring in $\mathrm{x}$ and $\mathrm{y}$ direction $172 \times 122 \mathrm{~mm}(150 \times 150 \mathrm{DPI})$ 


\section{Loads contribution to $\mathrm{X}$ direction displacement}

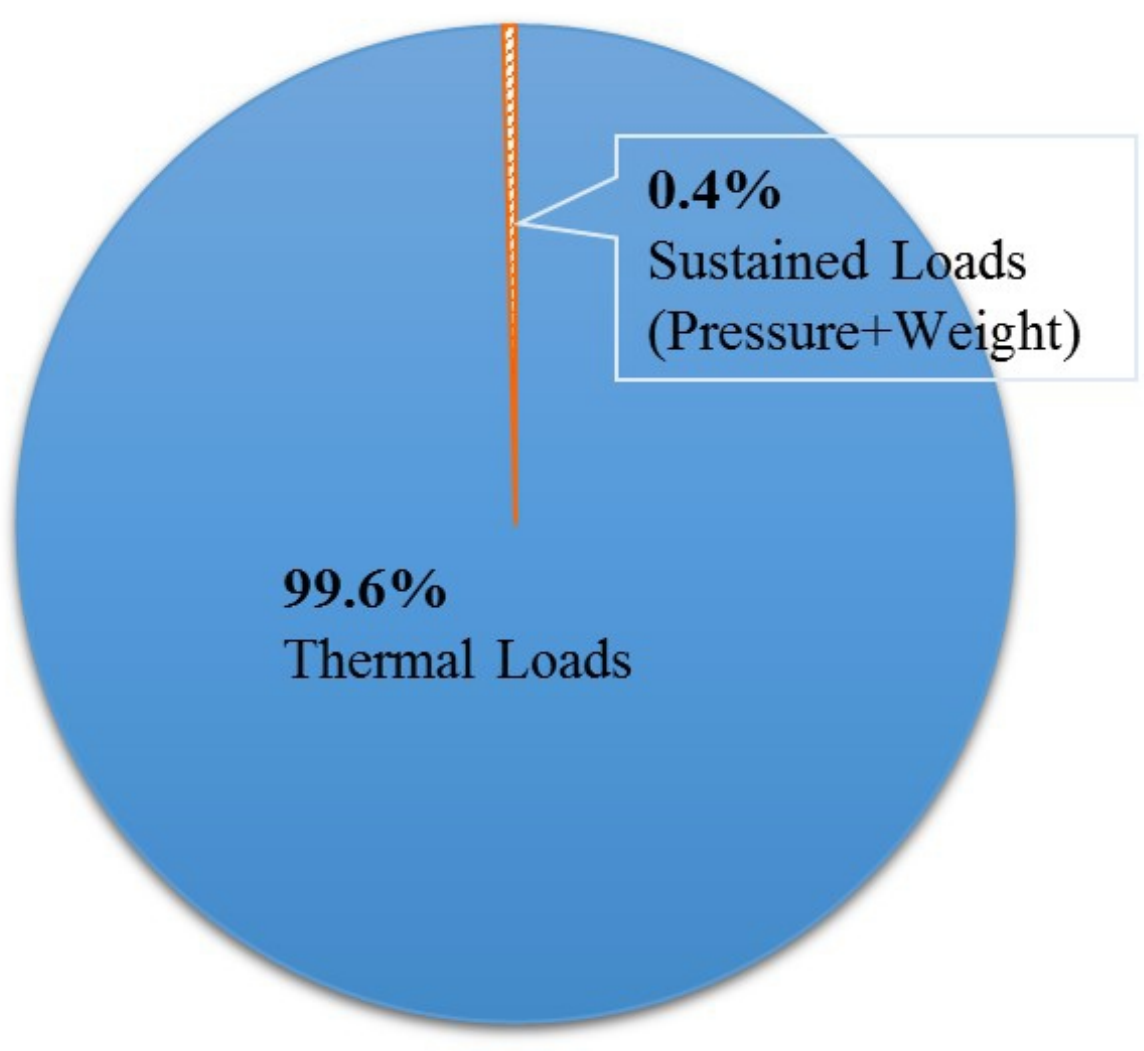

Figure 5: Pie chart representation of the $\mathrm{X}$ direction displacement $109 \times 102 \mathrm{~mm}(150 \times 150 \mathrm{DPI})$ 


\section{Loads contribution to primary part of $\mathrm{X}$ displacement}

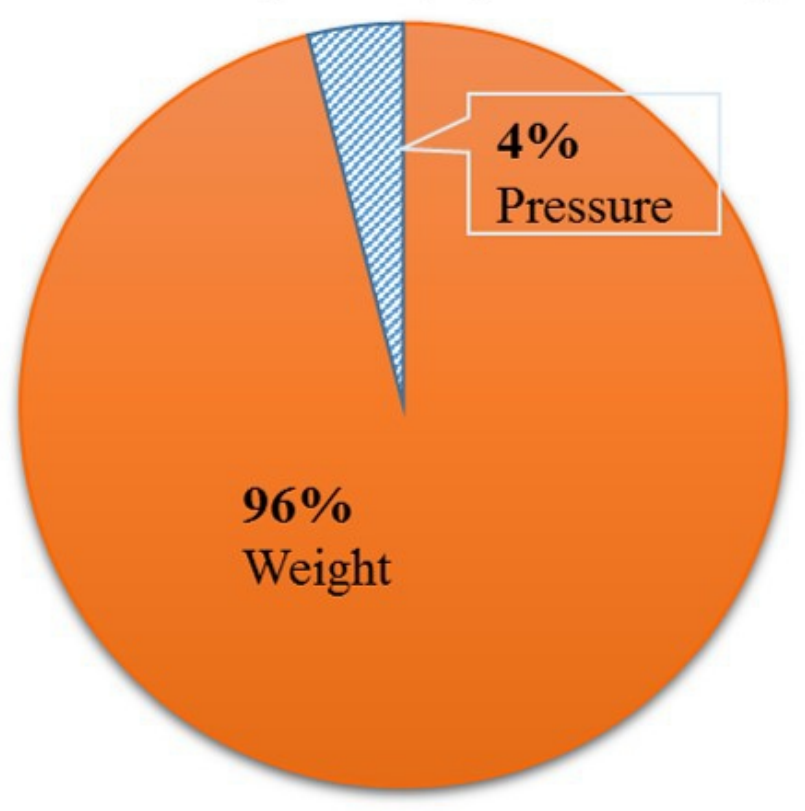

Figure 6: Pie chart representation of the primary $X$ direction displacement $119 \times 85 \mathrm{~mm}(150 \times 150 \mathrm{DPI})$ 


\section{Displacement composition for primary part of $\mathrm{X}$ displacement (Test model)}

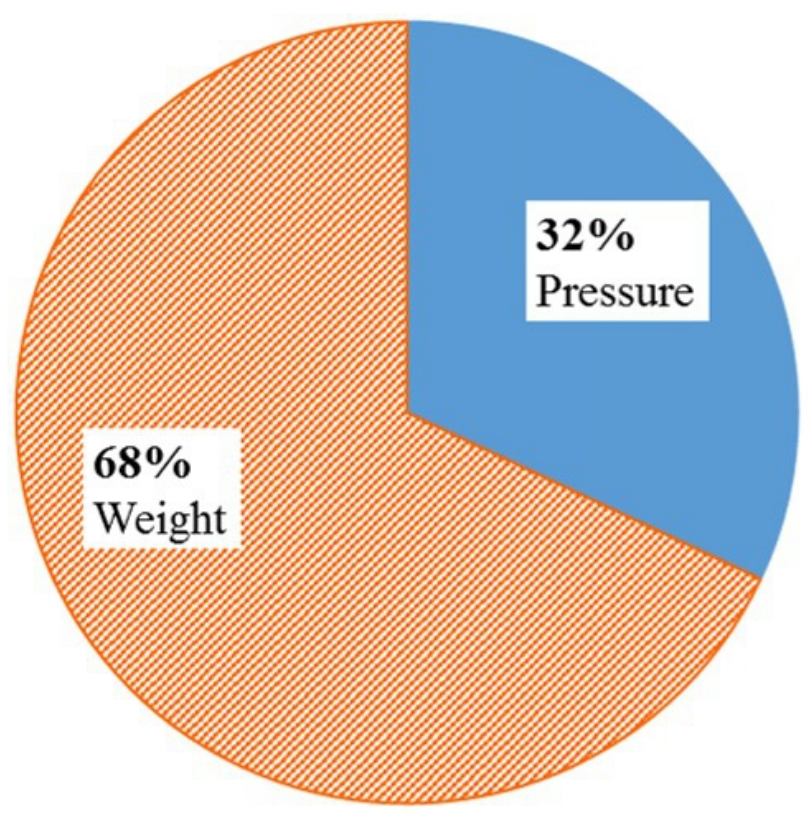

Figure 7: Pie chart representation of the primary $\mathrm{X}$ direction displacement (test model) $133 \times 102 \mathrm{~mm}(150 \times 150 \mathrm{DPI})$ 


\section{Loads contribution to $\mathrm{Y}$ direction displacement}

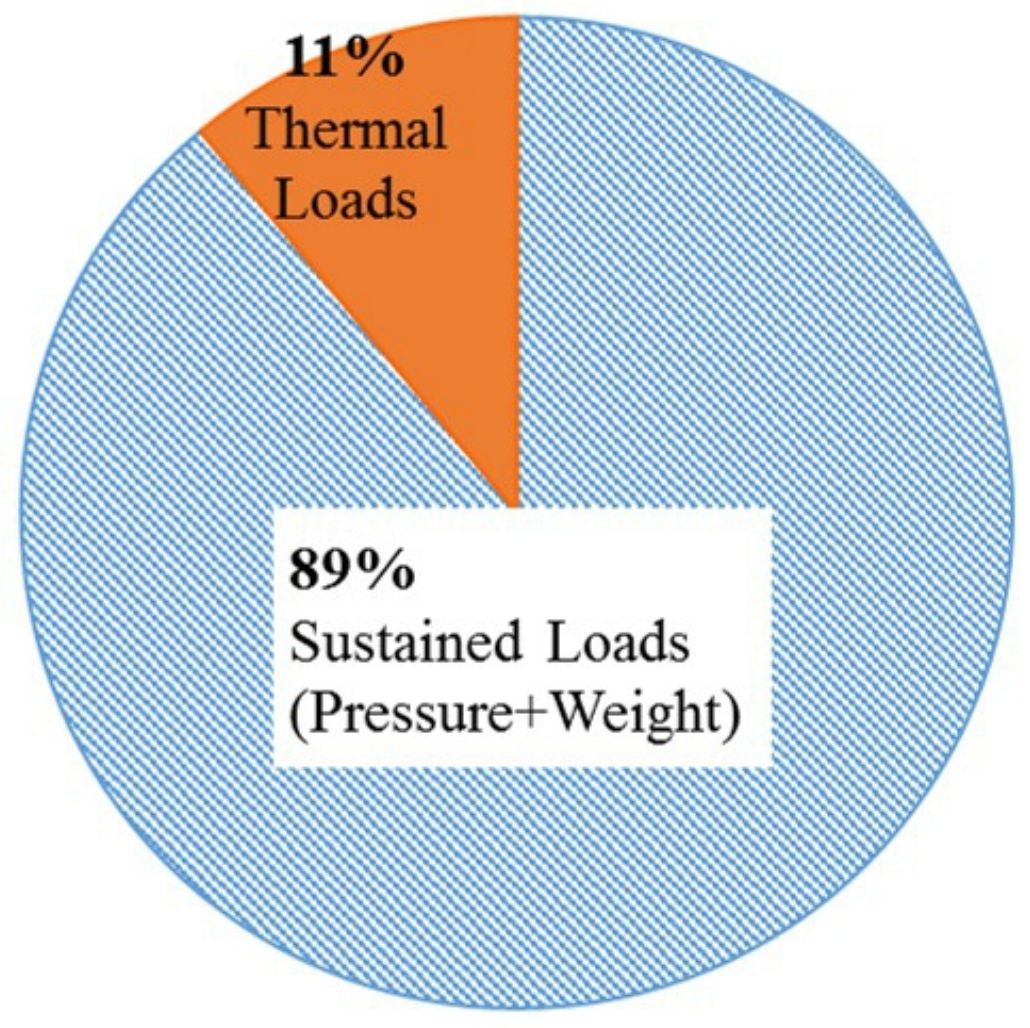

Figure 8: Y direction composition pie chart $103 \times 94 \mathrm{~mm}(150 \times 150 \mathrm{DPI})$ 


\section{Loads contribution to primary component of $Y$ displacement}

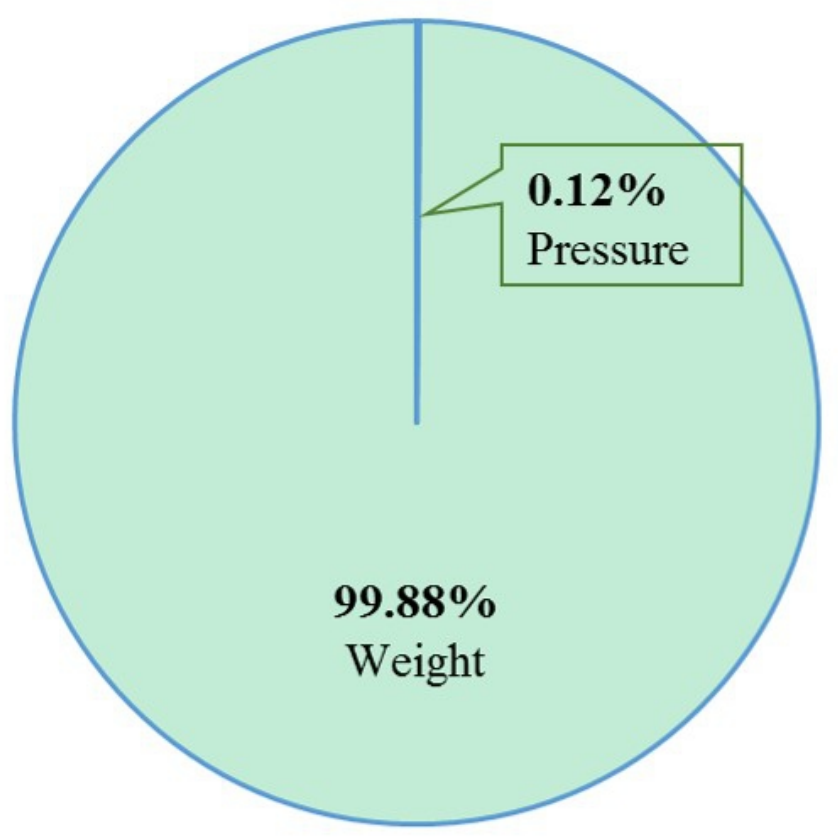

Figure 9: Pie chart display of subdivision of the primary part of $Y$ displacement $130 \times 96 \mathrm{~mm}(150 \times 150 \mathrm{DPI})$ 


\section{Displacement composition for primary part of Y displacement (Test model)}

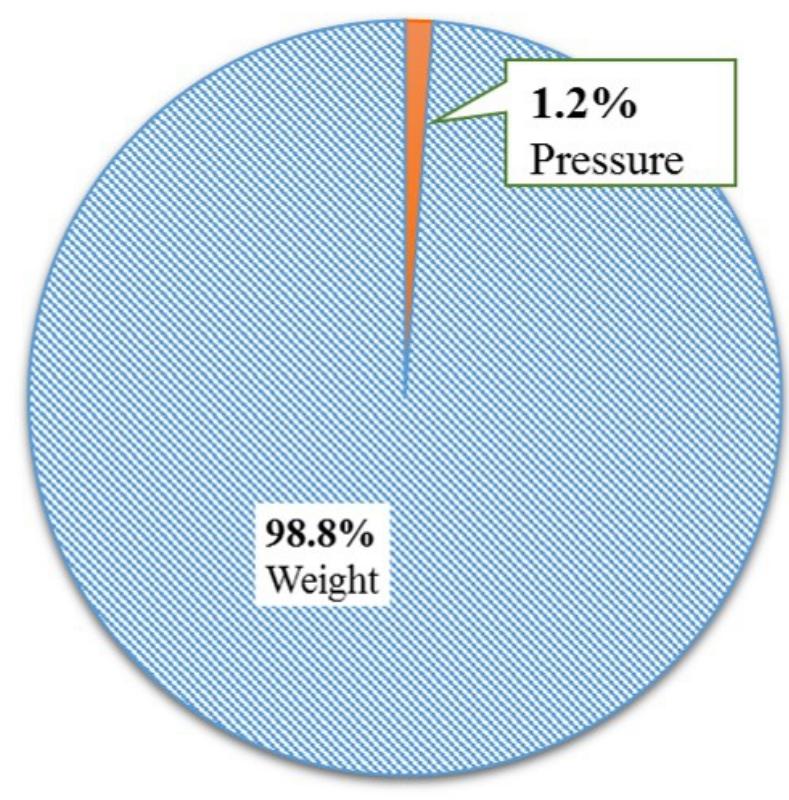

Figure 10: Pie chart representing the composition of primary $\mathrm{Y}$ displacement (test model) $137 \times 102 \mathrm{~mm}(150 \times 150 \mathrm{DPI})$ 


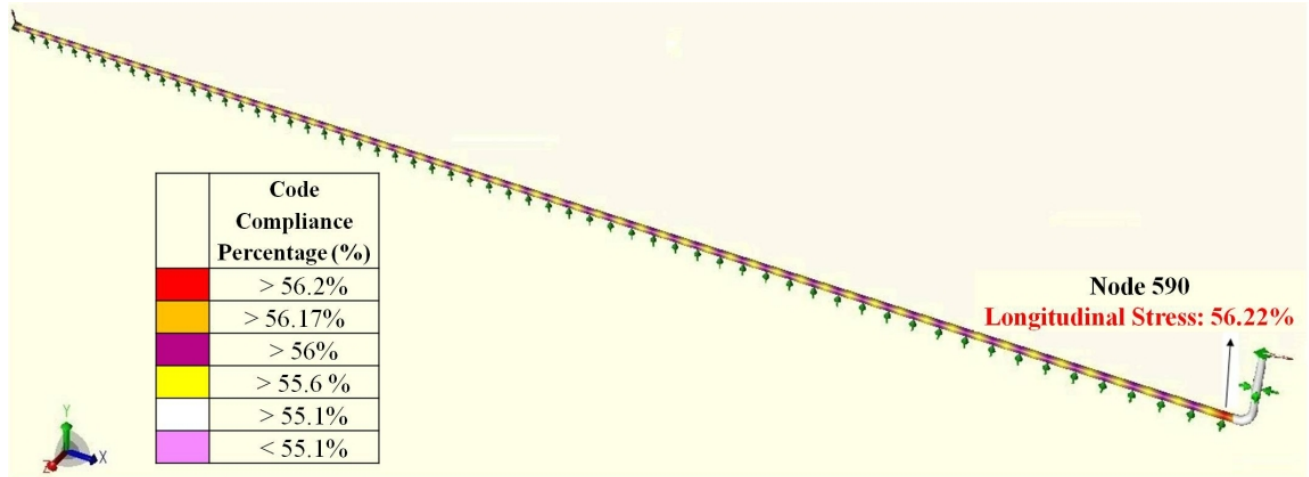

Figure 11: Longitudinal stress distribution diagram $360 \times 132 \mathrm{~mm}(150 \times 150 \mathrm{DPI})$ 


\section{Percentage composition of primary stress}

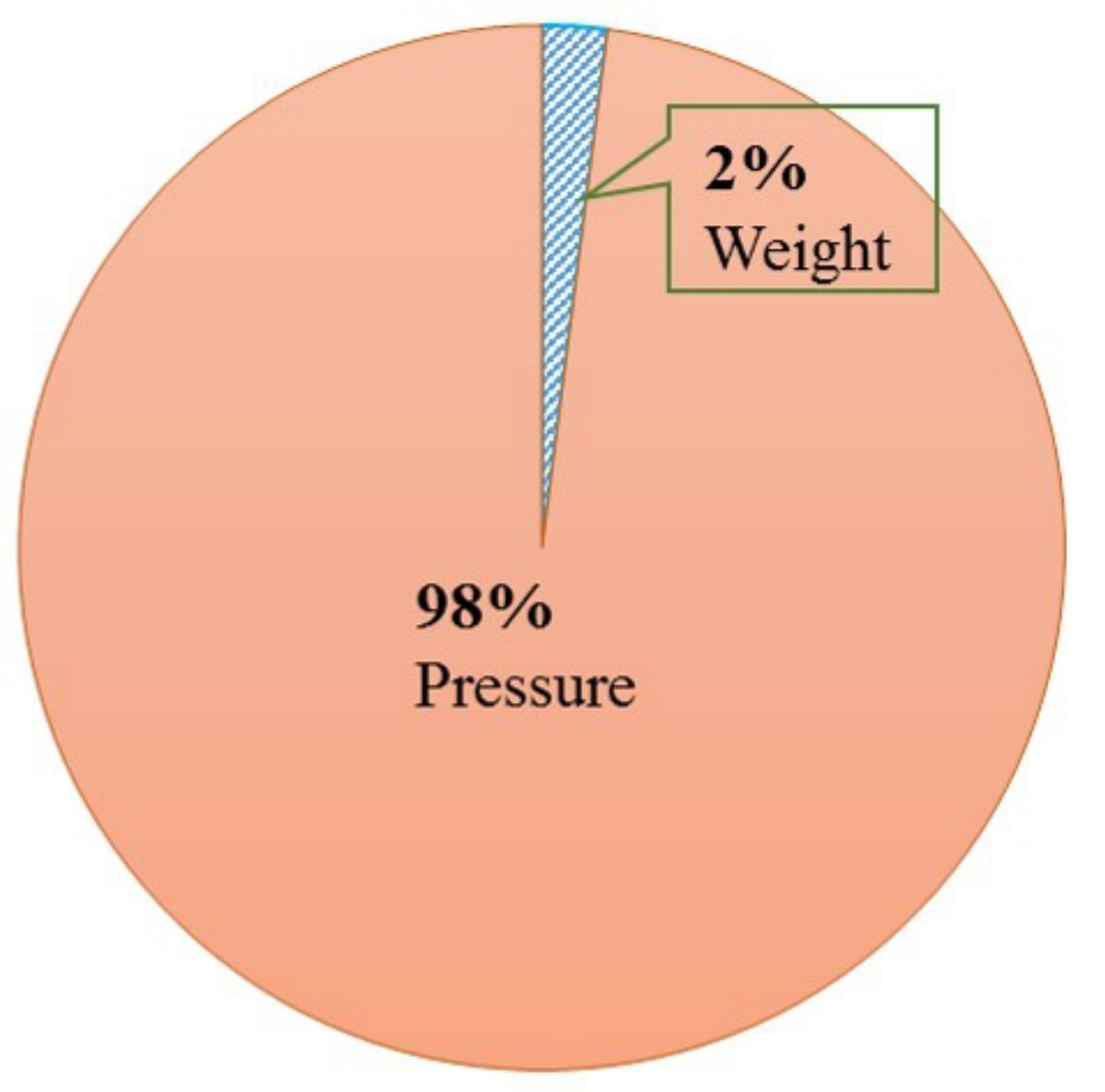

Figure 12: Pie chart representation of load primary stress contribution $92 \times 91 \mathrm{~mm}(150 \times 150 \mathrm{DPI})$ 


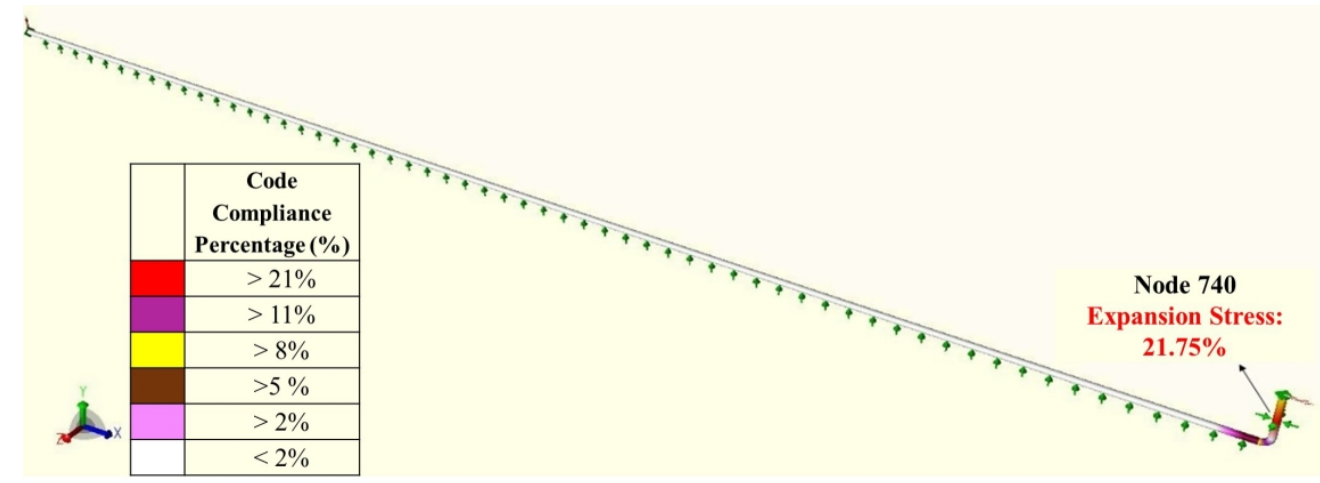

Figure 13: Thermal expansion stress distribution diagram

$355 \times 131 \mathrm{~mm}(150 \times 150 \mathrm{DPI})$ 


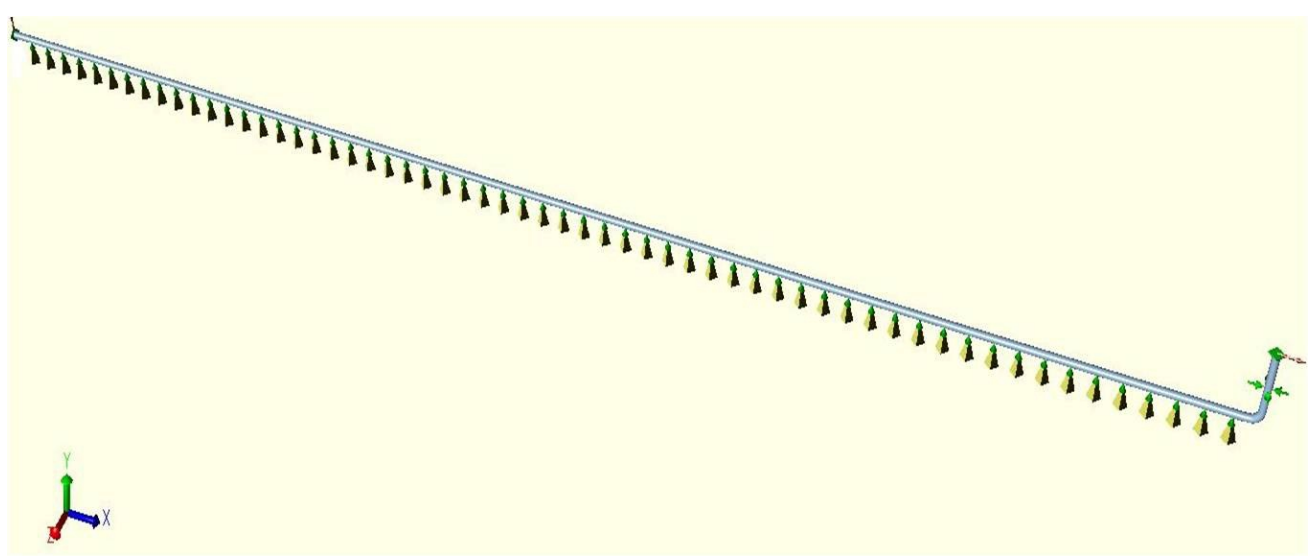

Figure 14: Feasibility of supports used in the pipeline model $359 \times 115 \mathrm{~mm}(96 \times 124 \mathrm{DPI})$ 
2018-12-17

\title{
A methodology for flexibility analysis of pipeline systems
}

\author{
Zahid, Umer
}

SAGE

Zahid U, Khan SZ, Khan MA, et al., A methodology for flexibility analysis of pipeline systems.

Proceedings of the Institution of Mechanical Engineers, Part E: Journal of Process Mechanical

Engineering, Volume 233, Issue 4, 2019, pp. 893-907

https://doi.org/10.1177/0954408918812275

Downloaded from Cranfield Library Services E-Repository 